\title{
Hughlings Jackson's Dr Z: the paradigm of temporal lobe epilepsy revealed
}

\section{DAVID C TAYLOR AND SUSAN M MARSH}

\section{From the Human Development Research Unit, Park Hospital for Children, Headington, Oxford}

"He who is faithfully analysing many different cases of epilepsy is doing far more than studying epilepsy. The highest centres ('organ of mind'), those concerned in such fits, represents all, literally all, parts of the body sensorially and motorially, in most complex ways, in most intricate combinations, etc. A careful study of many varieties of epileptic fits is one way of analysing this kind of representation by the 'organ of mind'."

J Hughlings Jackson (18881)

\section{Introduction}

On 10 January 1894, a distinguished physician died in London of an overdose of chloral hydrate. The event was of vital interest to Hughlings Jackson who attended the post-mortem examination with a bevy of witnesses. He begged his colleague Walter Colman "to search the taste region of Ferrier on each half of the brain very carefully." They were rewarded by finding "a very small focus of softening in that region (in the uncinate gyrus) of the left half of the brain." Jackson had thus discovered the most discrete and circumscribed lesion of the temporal lobe yet described to associate with the most detailed and elegant self report of psychomotor epilepsy yet published. For the physician, whom Jackson and Colman called "Dr Z" in their report in Brain ${ }^{2}$ had been Jackson's patient since 1877 and his own account of his epileptic experience had occupied six pages of Jackson's 1888 article "On a pariicular variety of epilepsy. . .." Jackson had himself witnessed several of Dr Z's attacks. The case enabled Jackson to argue that the complex symptomatology of the seizure was due to "reflex" effects of epileptic discharges in that area of brain. It is the paradigm of temporal lobe epilepsy.

Although the fact is not alluded to by Jackson these experiential epilepsies were already well known to asylum doctors. Griesinger describes them in his 1845 textbook $^{3}$ and Falret in his 1860 and 1861 articles $^{4}$ is well aware of their ominus significance. In 1826 Bouchet and Cazauvielh $^{6}$ described palpable induration of the temporal lobes in certain epileptics who had died in the Saltpetriere. Indeed, the record extends throughout medical history.

"I have often see that the attack was so short that the only thing necessary for the patient was to lean against a wall, or something similar and rub his face, and it ceased. Sometimes, however, he did not have to lean, he was seized by a confusion in the head, and a darkness in the eyes, and feeling it beforehand, he

Address for reprint requests: Dr DC Taylor, Park Hospital for Children, Headington, Oxford, England.

Accepted 15 May 1980 said an Ave Maria and before it had finished, the paroxysm had passed. There are some people who, after the paroxysm have absolutely no memory of their falling down or their affliction, while there are others, who remember and feel ashamed." Bernard of Gordon, 1542 (in Temkin, 1971). ${ }^{7}$

What is notable about Jackson's description of $\operatorname{Dr} \mathrm{Z}$ is that although the epileptic experience and the post mortem findings are recorded with meticulous precision there is scant biographical detail and no mention of the circumstances in which $\operatorname{Dr} \mathrm{Z}$ came to overdose himself with chloral hydrate. Jackson's account is totally mechanistic and lesion oriented. Despite his avowed interest in the "organ of mind" his separation from the interests of the asylum doctors is total. Thus a case placed at the frontier (and at the division) between neurology and psychiatry symbolises their subsequent parting to their mutual loss. 
In the context of a decade of personal study of patients with temporal lobe epilepsy $\mathrm{Dr} \mathrm{Z}$ has held a peculiar and increasing fascination. First, the incidence of suicide in the series of patients with temporal lobe epilepsy operated on by Murray Falconer at the Guys/Maudsley Neurosurgical Unit is at least 25 times that expected in the population largely due to the aggregation of all the factors known to be associated with increased suicide. ${ }^{8}$ Did $\operatorname{Dr} \mathrm{Z}$ commit suicide and what might have driven him to it? Would it happen, as sometimes happens now, that suicide was not mentioned in the death certificate? Second, personal research ${ }^{9} 10$ has shown that epileptic patients with small chronic lesions of the left temporal lobe have an increased susceptibility to schizophrenia. Could it have chanced that this association was already evident in this early, paradigmatic case? Third, in reviewing the pathological changes described in the resected temporal lobe in the 296 patients in that series there is no record of a lesion of the size and type described by Jackson and Colman, nor to our knowledge, is there in any other surgical series. And who was $\operatorname{Dr} \mathbf{Z}$ ?

The case of $\operatorname{Dr} Z$ was quite distinctive among the 50 cases of the "particular variety of epilepsy" on which Jackson drew for his 1888 paper. It consists almost entirely of a verbatim account written by $\operatorname{Dr} Z$. It contains extraordinary detail of mental processes disrupted $b y$ seizure activity, compelling reading for psychiatrists interested in the more chronic dissolution of mind which we label schizophrenia. The only comparable gem in the rest of the paper is the remark of another patient, W, p187) ${ }^{1}$ who explains "I get an idea in my head which is different from what I am thinking of." Dr Z's account was written after 17 years of epilepsy.

"I first noticed symptoms which I subsequently learnt to describe as petit mal when living at one of our universities in 1871. I was in very good health, and know of no temporary disturbing causes. I was waiting at the foot of a College staircase, in the open air, for a friend ... I I was carelessly looking around me, watching people passing, etc., when my attention was suddenly absorbed in my own mental state, of which I know no more than it seemed to me to be a vivid and unexpected 'recollection'; - of what, I do not know. My friend found me a minute or two later, leaning my back against the wall, looking rather pale, and feeling puzzled and stupid for the moment."

"My normal memory is bad, and a similar but much fainter feeling of sudden recollection of a forgotten fact is familiar. But in the abnormal states the recollection is much more instantaneous, much more absorbing, more vivid, and for the moment more satisfactory, as filling up a void which I imagine at the time I had previously in vain sought to fill."

"The recollection is always started by another person's voice, or by my own verbalized thought, or by what I am reading and mentally verbalize;"

“. . . ; there is never, however, as sudden a rush of returning normal consciousness as there has been of incipient abnormal consciousness; it is more gradual, and it is hard to say when it is complete, as it almost always leads to a passive and non-critical mental attitude, in which $I$ feel no originative mental impulse.",

"I have found myself just after a petit mal at a London Railway Booking Office, meaning to go to K . . . , and asking without hesitation for 'Second return to - to - that school, don't you know-", (or some such words) and being a good deal startled at my forgetfulness."

Of his physical condition at these times he and his friends combine to remark upon his pallor, a vacant look in the eyes, his tendency to "say 'Yes' with an air of complete assent to any remark made to me." And "occasionally make a slight half vocalized sound ... This latter . . . is somewhat like a modified and indistinct smacking of the tongue like a tasting movement and is generally accompanied by a motion of the lower jaw." It was the occurrence of this automatism which directed Jackson's search to the taste region of Ferrier.

"I had no haut mal before 1874 , and since then such attacks have recurred mostly at long intervals, sometimes of as much as eighteen months;"

In his major fits the muscular movements were variable but generally slight and only once lateralised to the right side. Some were purely akinetic. He experienced no hallucinations but was subject to several complex and prolonged automatisms.

"In October, 1887 I was travelling along the Metropolitan Railway, meaning to get out at the fourth station and walk to a house half a mile off. I remember reaching the second station, and $I$ then recollect indistinctly the onset of an 'aura', in which the conversation of two strangers in the same carriage seemed to be the repetition of something I had previously known-a recollection, in fact. The next thing of which I have any memory was that I was walking up the steps of the house (about half a mile from the fourth station), feeling in my pocket for a latch-key. I remembered almost at once that I had had a petit mal coming on at the second station, and was surprised to find myself where I was. I recollected that I had meant to reach the house not later than 12.45 , and had been rather doubtful in the train whether I should be in time. I looked at my watch and found it within a minute or two of 12.45. I 
searched my pocket for the ticket, which was to the fourth station, found it gone, and concluded that I must have passed the third station, got out at the fourth, given up my ticket and walked on as I had previously intended, though I had no memory of anything since the second station some ten or twelve minutes previously. I imagine that I had carried out my intention automatically and without memory."

"A fourth occasion is perhaps worth record. I was attending a young patient whom his mother had brought me with some history of lung symptoms. I wished to examine the chest, and asked him to undress on a couch. I thought he looked ill, but have no recollection of any intention to recommend him to take to his bed at once, or of any diagnosis. Whilst he was undressing I felt the onset of a petit mal. I remember taking out my stethoscope and turning away a little to avoid conversation. The next thing I recollect is that I was sitting at a writing table in the same room, speaking to another person, and as my consciousness became more complete, recollected my patient, but saw he was not in the room. I was interested to ascertain what had happened, and had an opportunity an hour later of seeing him in bed with a note of a diagnosis I had made of 'pneumonia of the left base.' I gathered indirectly from conversation that I had made a physical examination, written these words, and advised him to take to bed at once. I re-examined him with some curiosity, and found that my conscious diagnosis was the same as my unconscious, - or perhaps I should say, unremembered diagnosis had been. I was a good deal surprised, but not so unpleasantly as I should have thought probable."

While these amusing episodes give clear evidence of his capacity to act apparently rationally and with intent whilst not fully subject to the monitoring process usually attributed to the self, Jackson intimates, in the 1898 paper, ${ }^{2}$ that they were not always benign. He describes in detail an episode in which, during a fit, $\mathrm{Z}$ attempted playfully to prick him with a pin. But, "On another occasion there were post epileptic actions by $\mathrm{Z}$ during 'unconsciousness' of a kind which in a man fully himself would be criminal, and must have led to very serious consequences had not, fortunately, his condition been known. What he did was overloked by those concerned."

Dr $\mathrm{Z}$ also provided Jackson with fragments of his own writings during his epileptic automatisms. The examples generally came from clinical notes which $Z$ was writing when overcome by an attack. As $\mathrm{Z}$ himself remarks, they maintain normal grammatical structure whilst the words are grotesquely mal a propos. "My impression at the time that I was writing was that the words and sense were quite reasonable, and that I had kept within very familiar and prudent limits of expression." However the examples show otherwise; the words are a salad of loose associations. "For the last few days his beginning (starting to walk?) is more difficult for his tenderness of speechlessness and quick power of talk light swollenness of feet last three days". "For the last 18 mos years there has been some decided indefinite on $\mathrm{R}$ side in dress circle."

The foregoing at least allows some speculation as to whether this physician, with 20 years experience of managing his anticonvulsant medication, having experienced his own mental deterioration might not, in desperation, have taken his own life.

\section{Dr $\mathbf{Z}$ revealed}

Jackson mentions that the doctor died in January, 1894 and reference was made to the contemporary medical obituaries. In the British Medical Journal, 13 January 1894, a brief mention is made. ${ }^{11}$

"We regret to announce the death of Dr A T Myers, Physician to the Belgrave Hospital for Children and late Medical Registrar of St George's Hospital, which occurred at his residence, No 2 Manchester Square on the morning of January 10th. Dr Myers, who was well known by his researches into medicopsychological problems had been in failing health for many months. Dr Myers was among our oldest and most valued contributors."

The full obituary was published on 27 January $1894 .{ }^{12}$

ARTHUR THOMAS MYERS, MA, MD Cantab, FRCP

Arthur Thomas Myers, whose death we notice with great regret at the early age of 42 was born in 1851 at Keswick, his father being incumbent of St John's Church in that town. He was educated at Cheltenham and Trinity College, Cambridge. A scholar of Trinity, he finished his university career by taking a first class in the Classical Tripos and a second in the Natural Science Tripos. He obtained his Doctor of Medicine degree in 1881, and was made a Fellow of the College of Physicians in 1893. At St George's Hospital the late Dr Myers had a meritorious and distinguished career. He filled the office of housephysician, and was registrar in the medical wards for several years. He fulfilled the laborious duties of the latter post with singular patience, minuteness, and fidelity, and invented a system of indexing which has since proved of great value.

He was a member of the various Medical Societies, and physician to the Belgrave Hospital for Children. $\mathrm{He}$ wrote in the leading journals, and contributed various papers of interest, among which may be mentioned the Nervous Sequelae of Smallpox and a Case of Raynaud's Disease. His studies were of late years 
particularly directed towards abstruse problems connected with nerve diseases, and the subject of hypnotism as a treatment for disease-studies, perhaps, not the best suited for his own mental and bodily health.

Dr Myers was a distinguished athlete. At Cheltenham he was in the eleven, and played in the public school racket matches. At Cambridge he was captain of the Trinity eleven, and played in the tennis match against Oxford. Nature had, indeed, worthily designed him as one of those good "all round men" who are the glory of our public school education; but destiny thought fit to inflict upon him that terrible and inscrutable nervous malady which occasionally harassed him in early youth, and of late years advanced with relentless tread, baffling the most devoted medical skill and ultimately involving a fine intellect in ruin and confusion. There can be no doubt but for this Myers would have obtained the highest medical distinction.

His misfortune prevented his attaining to a post on the medical staff of a teaching hospital and this sad disappointment, intolerable to most men, was borne by him with singular patience. Even those who had the privilege of knowing him intimately never heard him repine, and in the intervals of illness he devoted himself energetically to his studies and to various athletic pursuits. After leaving the universities he was indeed known as an enthusiastic climber and skater, no mean cricketer, and an adept at tennis.

He had much subtlety and delicacy of intellect and belonged to a family of intellectual distinction and literary culture; his bent was largely towards psychological study, and the investigation and discussion of the more recondite phenomena of mind. By family relations, as well as by personal study, he was much interested in some of the problems which the "psychical researchers" aspire to solve. But his medical training led him to distrust many of their conclusions. To his sympathetic yet cautious pen are due some of the articles on these topics and incidents which have from time to time appeared in our columns. He was particularly happy as a reviewer, and in that capacity we were of ten indebted to his just, kindly, and suggestive work.

He was a devoted son, and in private life he was of a singularly kind and amiable disposition, given much to acts of hospitality and goodness to others. The slight brusqueness of his address, sometimes remarked by his juniors, was largely due to his infirmity, and he is mourned at the University and St George's by a large circle of friends. His history is tinged with a touch of melancholy, yet we can reflect that he has not lived in vain, for he has shown us the example of a brave man struggling against an unhappy fate, and there are many with all the advantage of intellect and physical health who have done less good work in the world than Arthur Myers."

The personal detail contained in Jackson's papers which matches with Myers' biography allows of no error that it was he who was $\mathrm{Dr} Z$.
The outspoken obituarist, apart from revealing his prejudice against "psychical researchers", clearly verifies our presumption that his terminal mental state might have been: "in ruin and confusion." Furthermore an initial glimpse through Dr Myers' list of publications by date (see Appendix I) starting with " $A$ Case of Raynaud's Disease" in 1885 to "Mind Cure, Faith Cure, and the Miracles of Lourdes" in the year prior to his death suggests that his interests had become at least somewhat recondite and "not the best suited for his own mental and bodily health." We might note his minuteness and fidelity, his indexing, his brusqueness, but more concrete and less impressionistic evidence is needed.

An inquest was held on 13 January 1894 but the death certificate makes no mention of mental disorder or suicide. Asphyxia-ComaEpilepsy-Brights Disease of kidneys, accelerated by a dose of narcotic medicine, are given as the cause of death. None of his obituaries is as informative as that in the British Medical Journal. The note of his death in the records at St George's Hospital is brief indeed. His name is mentioned in the minutes of the Committee of the Belgrave Hospital three times: first to note his arrival, second to regret his resignation, and third to record his death (and incidently, erroneously to send commiserations to his wife). However, through the discovery of Arthur Myers we uncover a major Victorian dynasty. A fascinating world of the intellectual dinosaurs.

His two brothers, his father and his grandfather all appear in the Dictionary of National Biography $(D N B)$ and a collection of Myers family papers is contained in the Library of Trinity College, Cambridge. Dr Myers' brother Frederic (1843-1901) was the best known and the family history has been researched (not always to its advantage) in detail by other scholars because he was the co-founder and the inspiration behind the Society for Psychical Research (SPR). Frederic was a prodigious scholar, as the $D N B$. records "At University few men have won more honours," but also a man. according to his own words, "of sensuous and emotional temperament" and given to "acts of swaggering folly" among which might be placed his swim across the Niagara River just below the Falls alone at night. Also he was advised to resign one of his University prizes on the suspicion that some of his methods might be construed as cheating. In 1869 he resigned his University lectureship for the purpose of helping to start the new movement for the 
Higher Education of Women. His early development as a poet was curtailed by his preoccupation from 1873 onwards with life after death. Despite this there is no doubting the intellectual and scientific rigour with which he pursued this interest. Family letters reveal his close attachment to Arthur who came to share his interest in the super-normal (a word together with "telepathy" and "veridical" invented by Frederic). How much did the curious traffic of Arthur's abnormal epileptic mental states influence their interest?

Through family connections, through marriage by scholastic acquaintance or psychological interests the Myers were connected with a galaxy of stars of the Victorian haute-culture. They were related to William Whewell, the natural philosopher and Master of Trinity College, Cambridge and to the explorer HM Stanley. Frederic was a close friend of the Duke of Albany (the youngest son of Queen Victoria) and he named William James among his close professional friends. Frederic was married to Eveleen Tennant by Dean Stanley in the Henry VII Chapel of Westminster Abbey on 13 March 1880. Their engagement prompted the charming letter from Arthur to Eveleen dated 3 January 1880 which is produced below with others as evidence of Arthur's prose style and handwriting over the period from 1876 to 1887 (fig 1b). Frederic died aged 58 years in 1901 in Rome where he was seeking an unconventional cure of his Bright's Disease.

Ernest, the second son (1844-1921) more con- ventional but also brilliant, was educated at Cheltenham and at Oxford. He becume a Fellow of Wadham College, Oxford in 1868. He resigned and was called to the Bar but never practised. He died aged 77 in Sussex.

Their father, Rev Frederic Myers survived the birth of his youngest son Arthur (16 April 1851) by only a few months, dying at the age of 40. (His brother Rev Thomas Myers died aged 50 and their father had died at the age of 60 years.) Their mother, née Susan Marshall removed to London and thence to Cheltenham to educate the three boys. Cheltenham was chosen as being the only Public School (that is private school) which really tolerated day boys.

Arthur followed Frederic and Ernest through the sohool with a career of all round brilliance which had come to be expected of a Myers. He won many prizes and played rackets, fives and cricket for the school. He followed Frederic to Cambridge in 1869 on a Foudation Scholarship, won the Winchester Reading Prize, and a half blue for tennis in 1873 (two years after the onset of his epilepsy). There is no mention in either school or college magazines of his being left handed. Also two years after the onset of epilepsy he came 12th in the 1st Class Classic's Tripos.

Aged 23 years in 1874 he started at St George's Hospital Medical School, obtained an MA in 1876, qualified as LSA (Licenciate of the Society of Apothecaries) in 1879 and MD in 1881. Although his MRCP (Membership of the Royal College of Physicians) was obtained in the fol-

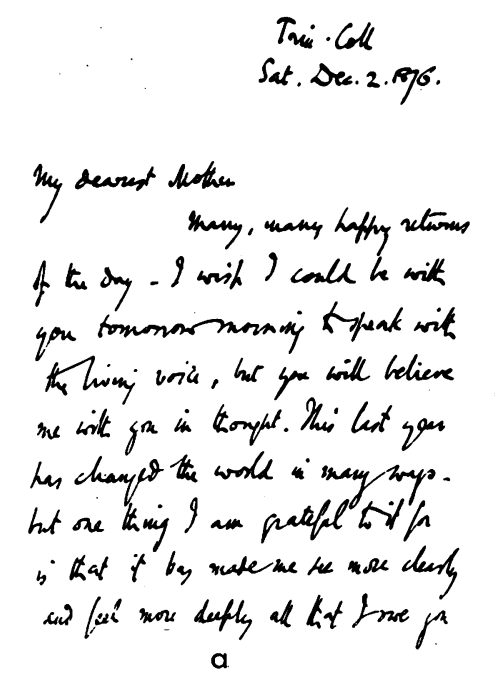

Tria Coll

Sat. Dec. 2.796.

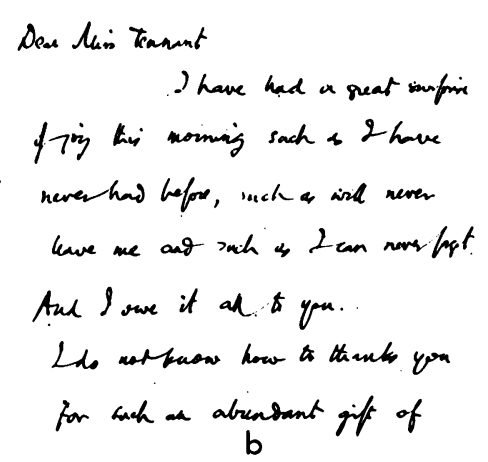

Fig 1

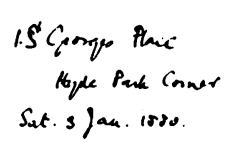

$$
\begin{aligned}
& \text { o Lonse K K I } \\
& \text { Hidera, s. } \\
& \text { Manterly }
\end{aligned}
$$

$$
\begin{aligned}
& \text { Nea, Zarl } \\
& \text { St is histrically, the thes }
\end{aligned}
$$

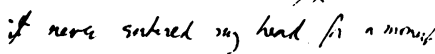

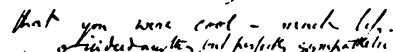

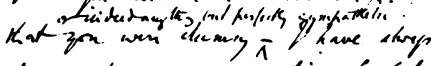

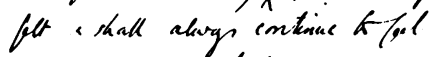$$
\text { most deafl, sialifal for gras armom }
$$

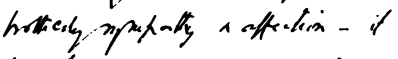$$
\text { has boen over mes again a }
$$$$
\text { very peat comport tha - 1-atmot }
$$

c 
lowing year aged 31, he was not made a Fellow until 11 years later in 1893, the year before he died, a circumstance which might suggest a negative evaluation by that august body. No record remains of who solicited or supported his Fellowship. He was unmarried.

Nothing in the form or the content of his published articles or private letters suggests mental deterioration. Indeed his graciousness, his warmth and his general tendency to trivialise his difficulty is everywhere apparent. Relatively few of his letters are dated, but a letter to Fred dated March, 1887 (fig 1c) reveals a less firm hand and accurate purpose than another dated December, 1876 (fig 1a) charmingly wishing his mother a happy birthday with only a hint of sadness which might refer to a severe episode in his own illness or to the recent tragic death of Annie.

Many of Myers' letters to the family made mention that he is experiencing only "les plus petits mals" but refer frequently to a sleep problem. The only medications recorded are chloral hydrate and potassium bromide.

His early papers on Raynaud's Disease and the Nervous Sequelae of Smallpox are dull but routine. A report to Nature on The Medical Index Catalogue developing in the USA, and his report as Medical Registrar in the St George's Hospital Gazette reveal no more than an ordinary interest in classification and orderliness. As judged by the elegance of his writing in Hypnotism at Home and Abroad (1890) it is not surprising that the British Medical Journal made good use of him as a reviewer and reporter. Mind Cure, Faith Cure and the Miracles of Lourdes (1893) written jointly with his brother Frederic, far from proving to be the wanderings of deranged minds bent on proving the existence of the supernatural, is a prolonged attack on the factitious and the fanciful, the fradulent and the slipshod in their field of enquiry. The article is 50 pages long, but considering the complexity of the subject matter, does not seem unduly verbose. Indeed the compactness of their withering prose is worth quoting, and their remarks on Lourdes and on Christian Science are given in Appendix III.

In addition to his medical writing Arthur Myers contributed about a dozen items to the Journal and the Proceedings of the SPR, wrote on hypnotism for Tuke's Dictionary and the biography of Esdaile for the $D N B$. It is interesting that he chose to write about Esdaile who had been a man of considerable talent and had achieved early in life great distinction as a sur- geon. His success with anaesthesia induced by hypnosis was undervalued by his peers and generally misunderstood. He retired from practice and died at the age of 50 , a broken and embittered man.

\section{Comment}

Myers' death was reported in The Times of Saturday 13 January 1894 and the inquest was reported on the 15th (see Appendix IV). The Bright's Disease was a surprise. Frederic was to die of it and since other Myers males had died young, a familial disorder is possible. Contemporary family members however, have kindly informed us that no familial pattern of kidney disease was known to exist.

Legally, Dr Myers did not commit suicide. We must still consider the probability of his having taken his own life. Nearly all the factors which are associated with suicide aggregate around him. Myers was bereft of his father at the age of a few months. He was single, he was physically ill, and ageing into the range of the peak incidence for suicide. $\mathrm{He}$ had been forced to retire from medical practice. Local Government records reveal that he began to share tenancy of No 2 Manchester Square with Dr Dawtrey Drewitt during 1893. Drewitt had no special interest in neurology or mental disorder, but it seems likely that the arrangement, which coincides with Myers' retirement from practice, was related to his deteriorating health. It was a recognised way of managing serious chronic illness, including mental illness. The means and the models for suicide were available. Two such deaths were close to him. The first was Annie's.

Annie was a cousin through his mother's family who was married to a manic drepessive who required much special care. Her sisters both died insane. A profound and frenzied love affair of the spirit grew up between Frederic and Annie. She is referred to in his privately circulated "Fragments of Inner Life" as Phyllis. Frederic believed that they had loved each other in a prior existence and that they would, after death, be forever re-united. His interest in life after death seems to stem from the beginning of this passionate platonic affair. But for reasons now unknown, on 1 September 1876 Annie having attempted to cut her throat with scissors, drowned herself in Ullswater. When the news reached Frederic he was on holiday in Scandinavia with Arthur. Could Arthur not have known the guilty secret?

The other tragic death was Gurney's in 1888 . 
Edmund Gurney was with Sidgwick, the cofounder with FWH Myers of the SPR. He died, during a meeting of the Society in Brighton, in his hotel bedroom, of an overdose of chloroform. Gurney was subject to trigemminal neuralgia. At his inquest, medical evidence was given by none other than Dr Arthur Myers. He stated that he had been prescribing chloral and belladonna for Gurney over many years but that they had discussed the use of chloroform in small doses for the relief of pain. As Gurney was known to suffer bouts of depression there was widespread belief that his death was suicidal, but without solid evidence the jury returned a verdict of accidental death.

The similarity to Myers' own death is very great. Dr Colman stated unequivocally that he found Myers "under the influence of some narcotic." Since Myers took chloral regularly as treatment presumably this implies an overdose, and there must have been some evidence of this to differentiate it from other causes of coma. There was no pathological evidence that status epilepticus or a single seizure caused the death. There rarely is in seizure deaths, but usually some interpretation is made from the state of the lungs and bronchi. It is not unlikely that Myers' friends, relatives and medical attendants would have protected him from the odious legal and religious consequences which then obtained of the jury returning a suicide verdict. But there is no certainty; the only available letter which reveals even mildly depressive sentiments is that of 1887 to Frederic (see fig 1c).

No evidence is now available which supports the obituarists' claim that epilepsy had brought Myers' intellect to "ruin and confusion." Besides it might arise from the medication, bromism or chronic chloral intoxication; or as prolonged seizures, "psychomotor status" or a post ictal confusional state, as well as from the more chronic inter-ictal schizophrenia-like psychosis. His epilepsy was mild throughout most of its course, but this is often the case where psychosis supervenes. ${ }^{13}$ Psychotic breakdown may follow the onset of epilepsy at any interval of years. ${ }^{14} 15$ Using patients with temporal lobe epilepsy operated on in the Guys/Maudsley/Kings Neurosurgical Unit we found that the factors which associate with schizophrenia-like psychosis were: a lesion of a chronic nonsclerotic type, in the left temporal lobe; left handedness; femaleness; and puberty onset epilepsy, ${ }^{913}$ Flor Henry ${ }^{13}$ also found more schizophrenia-like psychosis with left sided EEG foci in patients with temporal lobe epilepsy.
Dr Myers had a chronic non-sclerotic lesion. He was aged 20 years at the onset of epilepsy. He was clearly dysphasic in some of his attacks and he also had right sided motor signs which support the existence of a left lesion. The clinical picture of his attacks is similar to that shown by Feinde ${ }^{16}$ to result from periamygdaloid stimulation. All this goes some way to justify the deep position of the lesion described by Colman. Of particular interest in respect of a possible schizophrenia-like psychosis were the "thought-black" and the "two lines of thought," and the bizarre passivity which followed his attacks. But in a personal study of aura phenomena in 88 patients with temporal lobe epilepsy we could not find any association between these complex auras (sometimes called micropsychoses) and schizophrenic breakdown.

Criminal behaviour during complex automatisms is extremely rare. ${ }^{17}$ His automatisms were most unusually prolonged but we are uncertain whether the "criminal act" contributed to his resignation from practice. Waxman and Geschwind $^{18}$ and Bear and Fedio ${ }^{19}$ described certain traits as typifying patients with temporal lobe epilepsy; preoccupations with religious or spiritual issues, hypergraphia, irritability, meticulousness, etc. There are intimations of these in Dr Myers but they remain rather insubstantial. We are unclear about what actually did ruin his life. Was he really undone by the tiny lesion in the uncus? Such a lesion would be a true hamartien (the derivation of hamartoma) or "tragic flaw" of Greek drama. ${ }^{20}$ It would be a flaw which would lurk silently, the remote cause of increasing difficulties until it proved his eventual downfall.

But even the lesion must be called into question. The necropsy was made by $\mathrm{Dr}$ Walter Colman whom Jackson "begged . . . to call on me before ... in order to ask him to search the taste region of Ferrier on each half of the brain very carefully." The lesion thus discovered is pictured in fig 2 from the original report. It is an extraordinary diagram, the lesion so small, so circumscribed. "The existence of the patch and its position were verified in the fresh specimen by $\mathrm{Dr}$ Hughlings Jackson, Dr Dawtrey Drewitt. Dr James Taylor and Dr Guy Wood." (As Jackson had a special interest, Drewitt was a special friend, Taylor was Jackson's biographer, and Wood was then Jackson's house physician at Queen Square, they are not necessarily dispassionate observers.) Colman regrets that "unfortunately the uncinate region became so soft and friable during the hardening process 

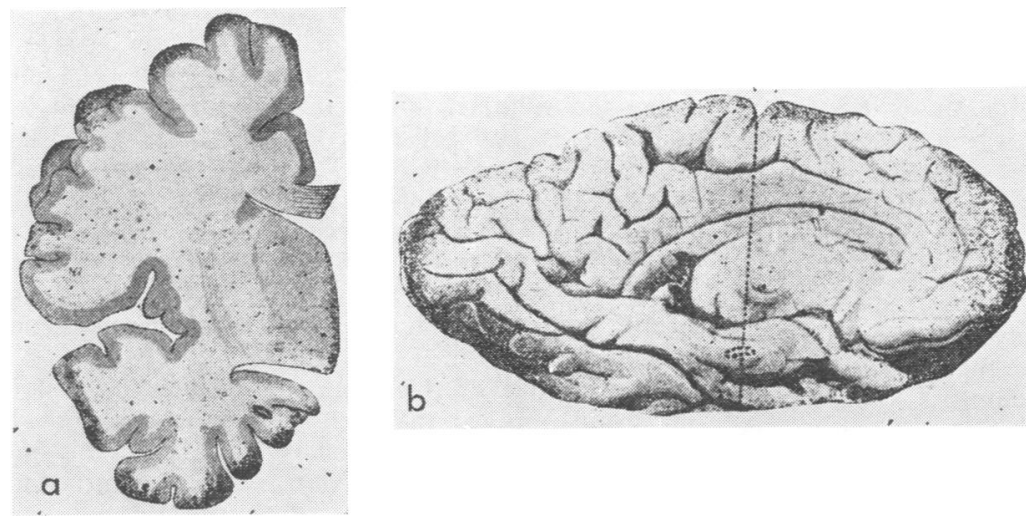

Fig 2 (a) Vertical section of left hemisphere (case of $Z$, from a tracing). Site of small cavity apparently due to softening, shown by black ring. (b) Drawing of internal surface of left hemisphere (case of $Z$ ). The black ring corresponds with the position of the cavity found. that it was impossible to make satisfactory sections, and the microscope did not throw any further light on the cause of the lesion." He further states that the examination was made 30 hours after death and that post mortem lividity was extreme and decomposition was rather advanced. The weather, he explains, was very warm and damp. The Meterological Office have kindly supplied the London weather report for the relevant 30 hours: "It was raining and the wind was southerly. Temperatures ranged from $40^{\circ} \mathrm{F}$ to a maximum of $44^{\circ} \mathrm{F}$." Why is Colman so apologetic and why do we need to know about the weather? Maybe Colman's comments conceal the fact that Dr Myers had been dead for rather more than 30 hours? Or could the lesion not be absolutely as clear as Jackson hoped? We are left with the feeling that although it is very likely, in view of the clinical history, that there was a small discrete lesion of the left temporal lobe, the curiosity described might not have been it, and that the truth lay only at a microscopic level. Perhaps a focal dysplasia? ${ }^{21}$

One mystery at least is solved. How was it that Hughlings Jackson managed, 17 years after first seeing his patient, to be in the right place at the right time to make the clinico-pathological association? Dr Myers died at No 2 Manchester Square. The house next door, No 3 , nowadays bears a plaque recording the fact that "John Hughlings Jackson, Physician, (1835-1911) lived here."

\section{Appendix I}

Dr Myers' Publications

1885 Myers AT. A case of Raynaud's disease. $\mathrm{Tr}$ Clin Soc Lond xviii, 336-8.

1886 Whipham T, Myers AT. On some chronic nervous sequelae of smallpox especially affecting the speech. Tr Clin Soc Lond xix, 164-89.

1886-7 Myers AT. A medical index-catalogue. IndexCatalogue of the Library of the Surgeon General's Office. US Army Vol VII Insignares-Leghorn. Nature, Lond. xxxv, 196.

1890 Myers AT. Hypnotism at home and abrodd. The Practitioner. xliv, 196-206, Lond.

1893 Myers AT, Myers FWH. Mind-cure, Faithcure and the Miracles of Lourdes. Proc Soc Psych Research Lond. ix, 160-209.

\section{Appendix II}

Transcript of the letters shown in fig 1

Trin Coll

Sat Dec 21876

My dearest Mother,

Many many happy returns of the day - I wish I could be with you tomorrow morning to speak with the living voice - but you will believe me with you in thought. This last year has changed the world in many ways - but one thing I am grateful to it for is that it has made me see more clearly and feel more deeply all that I owe you for your love and care - a debt I can never repay but which I can never forget to try to repay in thought and word and deed.

Your loving son, Arthur

1 St George's Place Hyde Park Corner Sat 3 Jan 1880

Dear Miss Tennant,

I have had a great surprise of joy this morning such as I have never had before, such as will never leave me and such as I can never forget. And I owe it all to you.

I do not know how to thank you for such an abundant gift of happiness present and to come for Fred's delight this morning was so over-flowing 
and so far reaching - and he has been such a brother to me all my life that I can never feel that his joy is not in part mine also. I have never known the world so brightened for me as it is today. Yrs affectionately Arthur Myers 9 Lower B St Monday Ev March 20/87

Dear Fred,

It is historically and absolutely true that it never entered my head for a moment that you were cool - much less that you were clumsy - or indeed anything but perfectly sympathetic. I have always felt and shall always continue to feel most deeply grateful for your warm brotherly sympathy and affection - it has been over and over again a very great comfort to me - I almost doubt if you can have realised sometimes how great - it may not of ten express itself in words but there it is - and it cannot be forgotten. Life is unsatisfactory - yes - But you have made me feel it less unsatisfactory. Yrs affectionately, A.T.M.

\section{Appendix III}

Extracts from "Mind Cure, Faith Cure and the Miracles of Lourdes"

"......How, it may be asked, do we know of the extraordinary beauty of the form which Bernadette perceived? We know this, it appears (p70) from the statement of the sculptor Fabisch, who made a statue of the Virgin which Bernadette regarded as a faithful copy of what she had seen. Of the pose and expression which he had thus faithfully reproduced, Fabisch informs us that 'he has seen nothing to equal them in suavity and rapture in the chefs d'oeuvre of the greatest masters,-of Perugino or Raphael'. It was fortunate that the task was committed to an artist so fully equal to the occasion; and the less favourable impression made upon one of ourselves by the sight of the statue in the grotto should not, perhaps, be placed in opposition to this decisive judgement of the sculptor himself."

"......We are all agreed that, whatever sense that we attach to matter and mind, what we call mind does in some way affect what we call matter, and there is nothing absurd in trying to make our mind affect the matter of our own bodies as strongly as it can.

Nothing absurd we say, in this effort itself. We do not say that some of its preachers have not done their best to make it so. The sixtieth edition of 'Science and Health, with Key to the Scriptures' by Mary Baker G Eddy, President of Massachusettes Metaphysical College lies before us. It begins with the following words: 'In the year 1866, I discovered the Science of Metaphysical Healing, and named it Christian Science. God had been graciously fitting me, during many years, for the reception of a final revelation of the absolute Principle of 'Scientific
Mind-healing". We did not close the book after this passage, and were rewarded by finding (p441) a demonstration, - whose naivete is only one step from the sublime, - of the essential necessity of our somewhat toilsome perusal: 'A Christian Scientist requires my work on Science and Health for his text book, and so do all his students and patients. Why? First: because it is the voice of Truth to this age, and contains the whole of Christian Science, or the science of healing through Mind. Second: - but the first reason really seems enough by itself.'

Now a style of this sort in a popular manual by no means proves that self-suggestion may not be successfully practiced by many readers on the lines there laid down. On the contrary, these gentle indications of personal merit, like the chariots and trumpets of the itinerant quack, may actually predispose some minds to the belief desired. But it shows us nevertheless that the buyers of the sixty editions are not likely to have much sympathy with science of a more humble and ordinary type, or to have taken the pains to record very accurately the cures attained by such a "high priori road'.....",

\section{Appendix IV}

Report from The Times, 15 January 1894, on the Inquest

"At the Marylebone Coroner's Court on Saturday afternoon Dr Denford Thomas held an inquest with reference to the death of $\mathrm{Mr}$ Arthur Thomas Myers, MD, MRCP, LSA aged 42 years, lately residing in Manchester Square. Mr Ernest Myers barister-atlaw identified the body as that of his brother who had suffered from epilepsy and had not practiced his profession since last October. For the purpose of inducing sleep his brother had long been in the habit of taking narcotics. Dr Frederick George Drewitt of Manchester Square stated that at about 8 o'clock on Tuesday morning, he was called by a servant to see Dr Myers. He found him lying insensible on the bed, and although six doctors kept up artificial respiration for 32 hours he remained in a comatose condition until he died on Wednesday. Dr Colman of Wimpole Street deposed that he had known the deceased for about six years but had never prescribed for him. He was called to see him on Tuesday and found him to be under the influence of some narcotic. He was present at the post mortem examination, which showed that the kidneys were diseased. Death, in his opinion was due to asphyxia, accelerated by a dose of some narcotic. Mr George Walter Prothero, tutor of King's College, Cambridge stated that he was with the deceased on Monday afternoon and evening and he had then seemed to be in unusually good spirits. The jury returned the following verdict: that the deceased died from asphxia when in a state of coma, following an epileptic attack, and accelerated by a dose of some narcotic while suffering from disease of the kidneys." 
We would like to express our appreciation to the many people who responded to our enquiries with such interest and generosity. In particular Rosemary Graham from Trinity College, Cambridge, the Librarians from the National Hospital Queen Square, St George's Hospital Medical School and King's College Hospital Medical School, The Cheltonian Society Secretary and the Westminster City Council Archevists.

\section{References}

1 Hughlings Jackson J. On a particular variety of epilepsy ("Intellectual Aura"), One case with symptoms of organic brain disease. Brain 1880; 11:179-207.

2 Hughlings Jackson J. Colman WS. Case of epilepsy with tasting movements and 'dreamy state'-very small patch off softening in the left uncinate gyrus. Brain 1898; 21:580-90.

3 Griesinger W. Die Pathologie und Therapie der Psychischen Krankheiten. Stuttgart, 1845.

4 Falret J. De l'état mental des épileptiques. Arch Gén de Méd 1860; 16:666-79.

5 Falret J. De l'état mental des épileptiques. Arch Gén de Méd 1861; 17:461-91 and 18:423-43.

6 Bouchet and Cazauvielh. De l'épilepsie considéré dans ses rapports avec l'aliénation mentale. Arch Gén de Méd 1826; 9:510-42.

7 Temkin O. In. The Falling Sickness. Baltimore: Johns Hopkins Press, 1971: 122.

8 Taylor DC, Marsh SM. Neuropathology and social pathology: the effects of small lesions in the temporal lobe. In: Proceedings on 'Tegretol in Epilepsy'. Geigy Pharmaceuticals, 1977: 21-6.

9 Taylor DC. Factors influencing the occurrence of schizophrenia-like psychosis in patients with temporal lobe epilepsy. Psychol Med 1975; 5: 249-54.

10 Taylor DC. Epileptic experience, schizophrenia and the temporal lobe. McLean Hospital Journal. Special Issue 1977: 22-37.

11 British Medical Journal 1894; Notice of death, p 94.

12 British Medical Journal. Obituary, p 223.

13 Flor Henry P. Psychosis and temporal lobe epilepsy. Epilepsia 1969; 10:363-95.

14 Slater E, Beard AW, Glithero E. The schizophrenia-like psychoses of epilepsy. Br J Psychiatry 1963; 109:95-150.

15 Taylor DC. The ontogenesis of chronic epileptic psychoses: A reanalysis. Psychol Med 1971; 1: 247-53.

16 Feindel W. In: Vinken PJ, Bruyn GW, eds. 'Handbook of Clinical Neurology', Volume 15. Amsterdam: Elsevier North Holland Publishing Co, 1974: 87-106.

17 Gunn J. Epileptic homicide: a case report. $\mathrm{Br} J$ Psychiatry 1978; 132:510-3.

18 Waxman SG, Geschwind N. Hypergraphia in temporal lobe epilepsy. Neurology 1974; 24:629-36.

19 Bear DM, Fedio P. Quantitative analysis of interictal behaviour in temporal lobe epilepsy. Arch Neurol 1977; 34:454-67.

20 Taylor DC, Marsh SM. In: Penry JK, ed. Epilepsy: The Eighth International Symposium. New York: Raven Press, 1977: 27-34.

21 Taylor DC, Falconer MA, Bruton CJ, Corsellis JAN. Focal dysplasia of the cerebral cortex in epilepsy. J Neurol Neurosurg Psychiatry 1971; 34:369-87. 